\title{
Study on Selenium Accumulation Characteristics of Different Tomato Varieties
}

\author{
Jichao Liao ${ }^{1, a}$, Guochao Sun ${ }^{2, b}$, Chunyan $\mathrm{Lu}^{3, \mathrm{c}}$ and Yi Tang ${ }^{2, \mathrm{~d} *}$ \\ ${ }^{1}$ College of Horticulture, Sichuan Agricultural University, Chengdu, Sichuan, China \\ ${ }^{2}$ Institute of Pomology and Olericulture, Sichuan Agricultural University, Chengdu, Sichuan, China \\ ${ }^{3}$ Chongzhou Educational and Training Center, Chengdu, Sichuan, China \\ a1498818502@qq.com, b6183090@qq.com, c174451929@qq.com, d95459425@qq.com
}

${ }^{*}$ Corresponding author. Jichao Liao and Guochao Sun contributed equally to this work.

Keywords: Tomato; Growth; Selenium accumulation

\begin{abstract}
A pot experiment was conducted to study the effects of soil application of selenium on the growth and selenium accumulation of different tomato varieties. The results showed that there were differences in the biomass, selenium content and selenium accumulation amount of tomato varieties. The biomass, selenium content and selenium accumulation amount of roots, stems and leaves of yellow cherry tomato reached the maximum, Fruit biomass of large tomatoes was the largest, followed by the yellow cherry tomatoes, the highest selenium content was red cherry tomatoes, followed by yellow cherry tomatoes, and the highest selenium accumulation amount was big tomatoes, followed by the yellow cherry tomatoes. In summary, selenium accumulation ability of yellow cherry tomatoes is strong, and its growth is the best.
\end{abstract}

\section{Introduction}

Selenium is one of the essential micronutrients for the human body. It can effectively prevent the production of cancer and tumors, increase the body's immunity, and prevent human aging [1-4]. The lack of selenium is significantly associated with many diseases for human, such as Keshan disease of residents in some areas of China. The main reason is that the intake of selenium by residents is insufficient [5]. Due to the lack of selenium induced diseases, it is possible to play a preventive role by supplementing selenium. Some diseases are significantly improved after selenium supplementation [6]. The content of selenium in the human body depends on the amount of selenium in people's foods, the amount of selenium in foods depends on selenium content in the soil and the accumulation ability of the crop to selenium, due to the selenium content is extremely unevenly distributed on the surface of the earth, and selenium deficiency is particularly serious in some areas (China's severely depleted selenium area accounts for about $30 \%$ of the country's land area) [7]. Therefore, understanding the selenium accumulation ability of crops has certain practical significance for human selenium supplementation. Tomato is a common fruit vegetable. It is not only nutritious but also convenient to eat. It has dual edible use of fruits and vegetables and is widely grown in the world [8]. To develop selenium accumulation tomatoes for daily diet, which can satisfy the human body's to demand for common nutrients and achieve the goal of selenium supplementation for selenium-deficient people. So, this study used five tomato varieties as materials to study the selenium accumulation characteristics of them by applying $5 \mathrm{mg} / \mathrm{kg}$ of selenium to the soil, in order to screen out the tomato varieties with good selenium accumulation ability.

\section{Materials and Methods}

Materials. The experiments were conducted at Sichuan Agricultural University $\left(30^{\circ} 42^{\prime} \mathrm{N}, 103^{\circ} 51^{\prime}\right.$ E), Wenjiang, China. The soil was taken from farmland around Sichuan Agricultural University (Chengdu campus) and was sandy loam soil. Its basic physical and chemical properties were $\mathrm{pH}$ 6.29 , organic matter $21.16 \mathrm{~g} / \mathrm{kg}$, total nitrogen $1.09 \mathrm{~g} / \mathrm{kg}$, total phosphorus $1.2 \mathrm{~g} / \mathrm{kg}$, total potassium $22 \mathrm{~g} / \mathrm{kg}$, available phosphorus $16.22 \mathrm{mg} / \mathrm{kg}$ and available potassium $156.2 \mathrm{mg} / \mathrm{kg}$. After retrieving it, 
spread it flat and dry it for one week, screened it with $1 \mathrm{~cm}$ sieve, and set aside.

Five varieties were used, including Y20-1 (Red cherry tomatoes), Small Tomato-4-1 (Yellow cherry tomatoes), Cafan-13-1 (Purple cherry tomatoes), Y6-1 (Green cherry tomatoes), stone' s-14-1 (large tomatoes). Tomato seeds are provided by the fruit and vegetable research institute of Chengdu campus of Sichuan agricultural university. $\mathrm{Na}_{2} \mathrm{O}_{3} \mathrm{Se} \cdot 5 \mathrm{H}_{2} \mathrm{O}$ is purchased from Chengdu kelong chemical reagent factory. All chemicals used in experiments were of analytical grade.

Experimental Design. The experiment was conducted in Sichuan Agricultural University (Chengdu Campus) from April to July 2017. In April 2017, Air-drying the soil, sieving with a $5 \mathrm{~mm}$ sieve, and weighing $10.0 \mathrm{~kg}$ in a plastic pot of $22 \mathrm{~cm} \times 29 \mathrm{~cm}$ (height $\times$ diameter) respectively. $\mathrm{Na}_{2} \mathrm{O}_{3} \mathrm{Se} \cdot 5 \mathrm{H}_{2} \mathrm{O}$ solution was added to the soil and the $\mathrm{Se}$ concentration was $5 \mathrm{mg} / \mathrm{kg}$. The soil was kept moist, kept for $40 \mathrm{~d}$, and mixed with soil from time to time. In May 2017, five varieties of tomatoes (red cherry tomatoes, yellow cherry tomatoes, green cherry tomatoes, purple cherry tomatoes, and large tomatoes) of the same size were selected and transplanted into pots, two plants were planted in each pot, and each treatment was repeated 3 times. After the ripening of the tomato fruit, the dry weight and selenium content of the root, stem, leaf, and fruit were measured.

Statistics Analyses. Statistical analysis was carried out by using SPSS 20.0 statistical software. The data were analyzed by one-way ANOVA, with the least significant difference at the $5 \%$ confidence level.

\section{Results and Analysis}

Biomass of Tomatoes. As can be seen from Table 1, there is a certain difference between the biomass of different organs of different tomato varieties. The biomass of roots ranged from $1.48 \mathrm{~g}$ to $1.94 \mathrm{~g}$, the biomass of stems ranged from $14.65 \mathrm{~g}$ to $21.99 \mathrm{~g}$, the biomass of leaf range from $4.98 \mathrm{~g}$ to $10.29 \mathrm{~g}$, and the biomass of fruit range from $0.31 \mathrm{~g}$ to $1.05 \mathrm{~g}$. Among them, the biomass of root, stem and leaf of yellow cherry tomato were significantly higher than other varieties. The order of the size is: yellow cherry tomato $>$ red cherry tomato $>$ purple cherry tomato $>$ large tomato $>$ green cherry tomato. The biomass of fruit is the large tomato. The order of the size is: large tomato $>$ yellow cherry tomato $>$ red cherry tomato $>$ purple cherry tomato $>$ green cherry tomato, the order of the root/shoot ratio is green cherry tomato $>$ large tomato $>$ purple cherry tomato $>$ yellow cherry tomato $>$ Red cherry tomatoes. It indicated that the yellow cherry tomatoes grew best under the condition of $5 \mathrm{mg} / \mathrm{kg}$ selenium.

Table 1 Biomass of tomatoes

\begin{tabular}{|c|c|c|c|c|c|}
\hline Variety & $\begin{array}{c}\text { Roots } \\
(\mathrm{g} / \text { plant DW })\end{array}$ & $\begin{array}{c}\text { Stems } \\
(\mathrm{g} / \text { plant DW })\end{array}$ & $\begin{array}{c}\text { Leaves } \\
(\mathrm{g} / \text { plant DW })\end{array}$ & $\begin{array}{c}\text { Root/Shoot } \\
\text { ratio }\end{array}$ & $\begin{array}{c}\text { Fruits } \\
(\mathrm{g} / \mathrm{plant} \mathrm{DW})\end{array}$ \\
\hline Red & $1.59 \pm 0.21 \mathrm{bc}$ & $17.42 \pm 0.83 \mathrm{~b}$ & $9.78 \pm 1.20 \mathrm{~b}$ & 0.06 & $0.46 \pm 0.03 \mathrm{c}$ \\
\hline Yellow & $1.94 \pm 0.10 \mathrm{a}$ & $21.99 \pm 0.82 \mathrm{a}$ & $10.29 \pm 0.18 \mathrm{a}$ & 0.06 & $0.56 \pm 0.04 \mathrm{~b}$ \\
\hline Purple & $1.67 \pm 0.15 \mathrm{~b}$ & $16.03 \pm 0.39 \mathrm{bc}$ & $8.69 \pm 0.34 \mathrm{bc}$ & 0.07 & $0.44 \pm 0.04 \mathrm{c}$ \\
\hline Green & $1.48 \pm 0.05 \mathrm{c}$ & $14.65 \pm 0.15 \mathrm{c}$ & $4.98 \pm 0.33 \mathrm{~d}$ & 0.08 & $0.31 \pm 0.04 \mathrm{~d}$ \\
\hline Large & $1.63 \pm 0.33 \mathrm{bc}$ & $14.97 \pm 2.09 \mathrm{bc}$ & $7.33 \pm 0.60 \mathrm{c}$ & 0.07 & $1.05 \pm 0.03 \mathrm{a}$ \\
\hline
\end{tabular}

Values are means \pm standard errors. The data followed by different lowercase indicate significant difference of $5 \%$ level.

Selenium Content in Tomatoes. It can be seen from Table 2, the effect of applying external selenium to soil on the selenium content of different tomato varieties is different. The selenium content in roots, stems and leaves of yellow cherry tomatoes was higher than other varieties. The selenium content in roots, stems, and leaves of yellow cherry tomatoes compared with the green cherry tomato with the lowest selenium content increased by $283.83 \%, 103.74 \%$, and $58.24 \%$, 
respectively, the order of the size is: yellow cherry tomato $>$ red cherry tomato $>$ purple cherry tomato $>$ large tomato $>$ green cherry tomato. The content of selenium in fruits was the highest in red cherry tomatoes, followed by yellow cherry tomatoes, and the order of selenium content in each organ of five different tomato varieties was $\operatorname{root}>\operatorname{leaf}>$ stalk $>$ fruit.

Table 2 Selenium Content in Tomatoes

\begin{tabular}{|c|c|c|c|c|}
\hline Variety & $\begin{array}{c}\text { Roots } \\
(\mu \mathrm{g} / \mathrm{g})\end{array}$ & $\begin{array}{c}\text { Stems } \\
(\mu \mathrm{g} / \mathrm{g})\end{array}$ & $\begin{array}{c}\text { Leaves } \\
(\mu \mathrm{g} / \mathrm{g})\end{array}$ & $\begin{array}{l}\text { Fruits } \\
(\mu \mathrm{g} / \mathrm{g})\end{array}$ \\
\hline Red & $112.54 \pm 0.92 \mathrm{~b}$ & $31.68 \pm 0.49 \mathrm{~b}$ & $44.01 \pm 0.56 \mathrm{a}$ & $28.46 \pm 0.57 \mathrm{a}$ \\
\hline Yellow & $141.44 \pm 1.29 \mathrm{a}$ & $34.86 \pm 0.56 \mathrm{a}$ & $46.08 \pm 0.72 \mathrm{a}$ & $26.95 \pm 0.58 \mathrm{a}$ \\
\hline Purple & $74.87 \pm 0.56 \mathrm{c}$ & $23.43 \pm 0.48 \mathrm{c}$ & $43.68 \pm 0.45 \mathrm{a}$ & $20.25 \pm 0.36 \mathrm{~b}$ \\
\hline Green & $36.85 \pm 0.43 \mathrm{e}$ & $17.11 \pm 0.32 \mathrm{~d}$ & $29.12 \pm 0.38 \mathrm{~b}$ & $13.87 \pm 0.24 \mathrm{c}$ \\
\hline Large & $60.20 \pm 0.56 \mathrm{~d}$ & $22.61 \pm 0.41 \mathrm{c}$ & $32.15 \pm 0.49 \mathrm{~b}$ & $15.39 \pm 0.47 \mathrm{c}$ \\
\hline
\end{tabular}

Values are means \pm standard errors. The data followed by different lowercase indicate significant difference of $5 \%$ level.

Selenium Accumulation Amount of Tomatoes. From Table 3, it can be seen that the selenium accumulation amount of different varieties of tomato is different at the same selenium level. The accumulation amount of selenium in roots, stems, and leaves of yellow cherry tomatoes reached the maximum. Compared with red cherry tomatoes, purple cherry tomatoes, green cherry tomatoes, and big tomatoes, the yellow cherry tomato roots increased by $53.34 \%, 119.55 \%, 403.10 \%$ and $179.65 \%$, respectively, the stems increased by $38.90 \%, 104.10 \%, 205.92 \%$, and $126.48 \%$, respectively, and the leaves increased by $10.22 \%, 24.98 \%, 227.12 \%$, and $101.30 \%$ respectively, the order of the size is: yellow cherry tomato $>$ red cherry tomato $>$ purple cherry tomato $>$ large tomato $>$ green cherry tomato. The accumulation amount of selenium in the fruits of the large tomato was the highest, compared with the green cherry tomato with the lowest selenium accumulation, the selenium accumulation amount in the large tomato fruit increased by $275.81 \%$. The order of the selenium content was as follows: large tomato $>$ yellow cherry tomato $>$ red cherry tomato $>$ purple cherry tomato $>$ green cherry tomato.

Table 3 Selenium accumulation amount of tomatoes

\begin{tabular}{|c|c|c|c|c|}
\hline Variety & $\begin{array}{c}\text { Roots } \\
(\mu \mathrm{g} / \mathrm{plant})\end{array}$ & $\begin{array}{c}\text { Stems } \\
(\mu \mathrm{g} / \mathrm{plant})\end{array}$ & $\begin{array}{c}\text { Leaves } \\
(\mu \mathrm{g} / \mathrm{plant})\end{array}$ & $\begin{array}{c}\text { Fruits } \\
(\mu \mathrm{g} / \mathrm{plant})\end{array}$ \\
\hline Red & $178.94 \pm 1.58 \mathrm{c}$ & $551.87 \pm 2.36 \mathrm{~b}$ & $430.42 \pm 2.08 \mathrm{~b}$ & $13.09 \pm 0.54 \mathrm{~b}$ \\
\hline Yellow & $274.39 \pm 1.92 \mathrm{a}$ & $766.57 \pm 4.24 \mathrm{a}$ & $474.39 \pm 2.55 \mathrm{a}$ & $15.09 \pm 0.08 \mathrm{a}$ \\
\hline Purple & $124.98 \pm 1.33 \mathrm{~b}$ & $375.58 \pm 2.27 \mathrm{c}$ & $379.58 \pm 1.86 \mathrm{c}$ & $8.91 \pm 0.42 \mathrm{c}$ \\
\hline Green & $54.54 \pm 0.87 \mathrm{e}$ & $250.66 \pm 2.18 \mathrm{e}$ & $145.02 \pm 2.76 \mathrm{e}$ & $4.30 \pm 0.47 \mathrm{~d}$ \\
\hline Large & $98.12 \pm 0.91 \mathrm{~d}$ & $338.47 \pm 2.35 \mathrm{~d}$ & $235.66 \pm 2.63 \mathrm{~d}$ & $16.16 \pm 0.43 \mathrm{a}$ \\
\hline
\end{tabular}

Values are means \pm standard errors. The data followed by different lowercase indicate significant difference of $5 \%$ level.

\section{Conclusions}

By applying exogenous selenium to the soil, the growth and selenium content of different varieties of tomatoes under the same selenium application conditions were studied. The results showed that there are some differences in biomass, selenium content and accumulation between tomato varieties, 
under the concentration of $5 \mathrm{mg} / \mathrm{kg}$ selenium, the biomass, selenium content and selenium accumulation amount of yellow cherry tomato were higher than those of other varieties, indicating that it had stronger selenium enrichment ability and promoted its growth. It indicates that which has more strong selenium accumulation ability and promotes its growth.

\section{Acknowledgements}

This work was financially supported by the Application Infrastructure Project of Science and Technology Department of Sichuan Province (2016JY0258).

\section{References}

[1] M. Vinceti, T. Filippini, S. Cilloni and G. Vivoli: Journal of Advances in Cancer Research Vol. 86(2000), p. 105.

[2] L. Björkhem-Bergman, U.B. Torndal, S. Eken, C. Nystrom, A. Capitanio, E.H. Larsen, M. Bjornstedt and L.C. Eriksson: Journal of Carcinogenesis Vol. 26(2005), p. 125.

[3] X. Peng and H.M. Cui: Journal of Chinese Veterinary Science Vol. 8(2010), p. 867.

[4] J. Zhang, X. Gao, L. Zhang and Z. Yang: Journal of Acta Nutrimenta Sinica Vol. 22(2000), p. 219.

[5] Y.Z. Xiang, X.H. Wang, J. Wang, W.M. Zhang S.L. Song, L. Wang, F.R. Qu and Y. Liu: Journal of Hygiene Research Vol. 39(2010), p. 466.

[6] M.Y. Liu, Y. Li and X.X. Gao: Journal of Chinese Journal of Clinical Nutrition Vol. 11(2003), p. 295.

[7] H.S. Liu: The effects of selenium on tomato and lettuces and the characteristics of selenium accumulation, Yangzhou University (2009).

[8] L.H. Guo: Journal of Agriculture and technology Vol. 37(2017), p. 119. 